\title{
Strabismus in Generations and Among Siblings
}

\section{Sabina Shrestha ${ }^{1}$, Chunu Shrestha ${ }^{2}$, Aparajita Manoranjan ${ }^{3}$ and Sushan Man Shrestha ${ }^{4}$}

${ }^{1}$ Department of Ophthalmology, Kathamandu Medical College Teaching Hospital, Sinamangal, Kathmandu, Nepal

${ }^{2}$ Kedia Eye Hospital, Bahuari, Nepal

${ }^{3}$ Professional Support Service Nepal

${ }^{4}$ M.Sc. (Statistics), MPH

\begin{abstract}
Introduction: Strabismus has been observed among family members in involved families. The study was conducted to document manifest strabismus running in generations and among siblings of strabismic patients.
\end{abstract}

ABSTRACT

Methods: It was a hospital based prospective study conducted from May to November 2017. Strabismic patients with ocular deviation visiting Department of Paediatric Ophthalmology and strabismus were enrolled using specially designed proforma. Detailed ocular examinations were done and family history obtained regarding the presence of strabismus. Family tree was drawn for those with positive family history.

Results: A total of 78 participants completed the study with $48.7 \%$ males. Family history of strabismus was present in $56.4 \%$. Strabismus was present in two generations in $45.45 \%$, in three generations in $18.2 \%, 1^{\text {st }}$ and $3^{\text {rd }}$ generation in $18.2 \%, 1^{\text {st }}, 2^{\text {nd }}$ and $4^{\text {th }}$ generation in $4.5 \%$ and among siblings only in $13.6 \%$. Among those with positive family history, exotropia was present in $75 \%$ and esotropia in $25 \%$. Among exotropes, manifest deviation was present in $47.7 \%$ and intermittent exotropia in $27.3 \%$. Among esotropes, congenital esotropia was present in $9 \%$ and accommodative esotropia in $16 \%$. First degree relatives were affected in $45.45 \%$ of strabismic patients among which 55\% had manifest exotropia, $20 \%$ had intermittent exotropia, 15\% had accommodative esotropia and $10 \%$ had congenital esotropia.

Conclusions: Strabismus was found in different generations in $56.4 \%$ strabismic patients. Two generations were involved in $45.45 \%$, three generations in $18.2 \%, 1^{\text {st }}$ and $3^{\text {rd }}$ generation in $18.2 \%, 1^{\text {st }}, 2^{\text {nd }}$ and $4^{\text {th }}$ generation in $4.5 \%$ and siblings only in $13.6 \%$. Genetic factors appear to be significant in strabismus in Nepalese population and it requires to be substantiated with further larger studies.

Key words: Esodeviation; exodeviation; generations; siblings; strabismus

Correspondence: Sabina Shrestha, Kathmandu Medical College Teaching Hospital, Sinamangal, Kathmandu, Nepal. Email: sabina_drs@hotmail.com

DOI: $10.3126 / \mathrm{mj}$ sbh.v20i1.24777

Submitted on: 2019-07-10

Accepted on: 2020-12-27 


\section{INTRODUCTION}

Strabismus has been observed among family members in the involved families as genetic factors also play a role in its development. Hippocrates had stated that bald persons had descended from bald parents, blue eyed persons from blue-eyed parents and strabismic children from squinting parents. ${ }^{1}$

About $30 \%$ of children born to a strabismic parent will themselves develop strabismus according to large scale studies. ${ }^{2}$ At the same time, twin studies reveal a concordance rate for monozygous twin of $73 \%$ to $82 \%$ and $35 \%$ to $47 \%$ for dizygotic twins. 3,4 Less than $100 \%$ concordance suggests that intrauterine, perinatal or environmental factors alter the expression of the strabismic genotype.

Studies of heritability of strabismus, its running in generations and families are conducted in the western world only. Therefore, we aim to find out how strabismus runs in generations and among siblings in our population.

\section{METHODS}

It was a hospital based cross sectional quantitative study. The study duration was of seven months, from May to November 2017. Strabismic patients with manifest deviation with no associated syndromes visiting Department of Paediatric Ophthalmology and Strabismus in a tertiary level eye hospital of Kathmandu during the study period were enrolled. Especially designed proforma was used for documenting patient demographics and the clinical examination findings. Family history of the participants was obtained regarding the presence of strabismus in three generations. Of those strabismic participants with positive family history, family tree was drawn. However, two participants who could

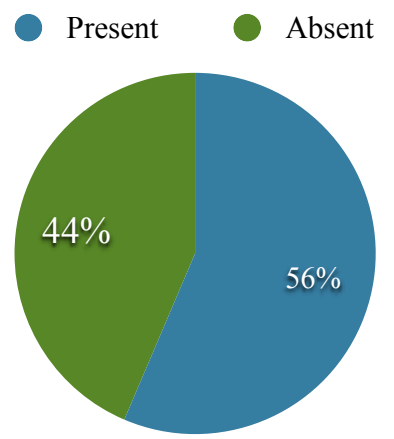

Figure 1. Family History of Strabismus recall the positive family history of strabismus even in the fourth generation were also enrolled. Those strabismic patients who cannot give family history of strabismus were excluded from the study. Convenient sampling was done and informed consent was taken from the participant or guardian if minor for enrollment in the study. However, the family members with strabismus were not examined and only manifest deviation of the family members were documented. This is the limitation of the study. Data were entered in excel and analysis was done using SPSS (version 20) and data were expressed in frequency and percentage as per the need.

\section{RESULTS}

A total of 78 participants completed the study with $48.7 \%$ males and $51.3 \%$ females. Among them $52.56 \%$ were of Indo-Aryan origin and $47.44 \%$ were of Tibeto-Burman origin. Among the participants with positive family history, exodeviation was present in $75 \%$ and esodeviation in $25 \%$.

First degree relative of patients with strabismus were affected in $45.45 \%$ among which $55 \%$ had manifest exotropia, 20\% intermittent exotropia, $15 \%$ had accommodative esotropia and $10 \%$ had congenital esotropia. However, the family members were not examined to document whether they also had the same type of strabismus.

\section{DISCUSSION}

Thirteen percent of parents of strabismic probands had strabismus versus a $3 \%$ incidence in the general population. ${ }^{5}$ Maumenee and associates

Table 1. Strabismus in Generations

\begin{tabular}{|l|r|r|}
\hline Generation & Frequency & Percentage \\
\hline 2 Generations & 20 & $45.45 \%$ \\
\hline 3 Generations & 8 & $18.2 \%$ \\
\hline $\begin{array}{l}\text { 1st and 3rd } \\
\text { Generation }\end{array}$ & 8 & $18.2 \%$ \\
\hline $\begin{array}{l}\text { 1st, 2nd and 4th } \\
\text { Generation }\end{array}$ & 2 & $4.5 \%$ \\
\hline Siblings only & 6 & $13.6 \%$ \\
\hline Total & 44 & $100 \%$ \\
\hline
\end{tabular}




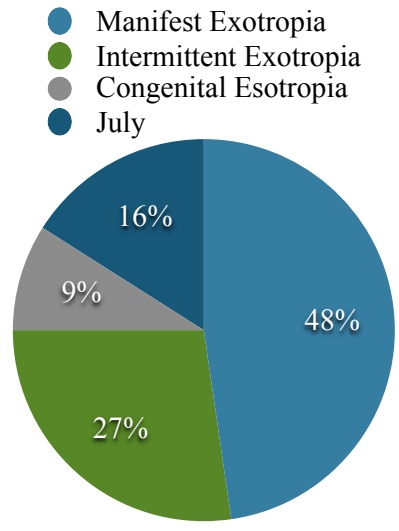

Figure 2. Distribution of Types of Deviation among those with positive family history

analysed the predegrees of 173 families containing probands with esotropia onset before the age of six months in the absence of major refractive error. ${ }^{6}$ The results suggested multifactorial or Mendelian codominant inheritance pattern.

The examination of a cohort of 7100 strabismic patients from 12 published family studies had revealed that 2171 strabismic probands $(30.6 \%)$ had a close relative with strabismus. ${ }^{3}$ Families were usually concordant for either esotropia or exotropia. However, families with both forms have been reported. This finding may reflect the presence of two relatively common genes or one gene with variable expressivity. ${ }^{6,7}$

Ocular alignment also depends on several complex sensory and motor pathways in the retina, thalamus, brainstem and visual cortex apart from the development and functioning of extraocular muscles and orbit according to V Parikh et al. ${ }^{8}$ The current evidence indicates the inheritance pattern of the common forms of strabismus is complex. ${ }^{1,6,9}$ It is also likely that both genes and environment contribute to the occurrence of strabismus. ${ }^{10}$ However, the heritability values for strabismus is likely to be underestimated as about $15-20 \%$ of strabismus is associated with non-ocular conditions like low birth weight, global central nervous system defects ${ }^{11}$ and there can also be incomplete detection of phoria, microtropias and monofixation syndromes. This can be the reason why only $56.4 \%$ of strabismic patients had strabismus running in generations and among siblings in the present study.

It has been found that esotropia is more common in the white population of United States and Europe $^{11,12}$ while exotropia is more frequent in the Asian population and among black populations of United States and Africa. ${ }^{3,12,13}$ This can be the reason why exotropes were more common in the present study also.

The advanced maternal age, cigarette smoking during pregnancy and low birth weight $(<1500$ gm) also contributed to the risk of strabismus according to Collaborative Perinatal Project. ${ }^{14}$ However, when corrected for these environmental risk factors, the odds ratio for heritability of concomitant strabismus remained significant. ${ }^{15}$ However, we have not looked for the association between strabismus and the history of smoking and advance maternal age.

\section{First Degree Relatives}

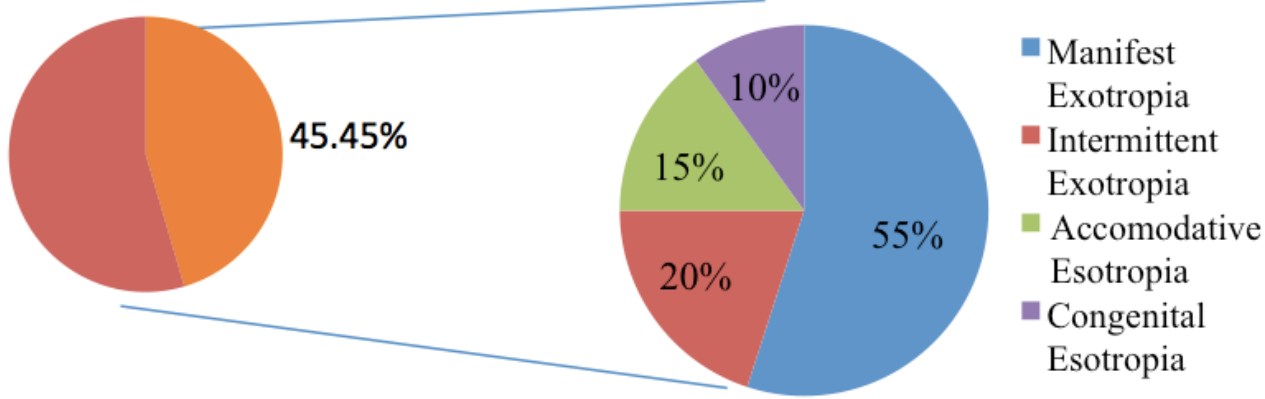

Figure 3. Distribution of types of deviation among those with strabismus in first degree relative 
The relative risk for first degree relatives of an affected proband with common strabismus is estimated to be between three and five. ${ }^{8,14,16,17}$ In the present study also, first degree relatives were affected in $45.45 \%$.

First degree relatives of patients with hypermetropic accommodative esotropia was affected $26.1 \%$, with infantile esotropia $14.9 \%$, with anisometropic esotropia $12.1 \%$ and with exotropia $4 \%$ in a study by $\mathrm{N} \mathrm{G}$ Zikas et al. ${ }^{18}$ However, in our study, patients with first degree relatives affected included manifest exotropia in $55 \%$, intermittent exotropia in $20 \%$, accommodative esotropia in $15 \%$ and congenital esotropia in $10 \%$.

Sclossmann and Priestley found that $47.5 \%$ of their patients with strabismus, $48.9 \%$ with esotropia and $36.8 \%$ with exotropia, belonged to families with two or more affected members. ${ }^{7}$ Aurell et al. found that $17.6 \%$ of babies born into families with a first degree relative affected by convergent strabismus developed constant or intermittent esotropia by age of six years. ${ }^{19}$ Another study has reported the familial incidence of strabismus to be as high as $65 \% .^{20}$
As only the family members with manifest deviation of strabismic participants were studied, the presence of strabismus may be underestimated in the present study. Apart from that, other ocular conditions, central nervous system status, intrauterine, perinatal and environment factors also play a role in the development of strabismus. These can be the reason why only $56.4 \%$ of strabismic patients had family history of strabismus in the present study.

\section{CONCLUSIONS}

Strabismus was found in different generations in $56.4 \%$ strabismic patients among which $75 \%$ were exotropes and $25 \%$ were esotropes. Two generations were involved in $45.45 \%$, three generations in $18.2 \%, 1^{\text {st }}$ and $3^{\text {rd }}$ generation in $18.2 \%, 1^{\text {st }}, 2^{\text {nd }}$ and $4^{\text {th }}$ generation in $4.5 \%$ and siblings only in $13.6 \%$. Genetic factors do have role in strabismus and our findings support the same in Nepalese population. However, our finding requires to be substantiated with further larger studies.

\section{ACKNOWLEDGEMENTS}

The authors would like to thank Mr. Karna Deshar for computer works.

To cite this article: Shrestha S, Shrestha C, Manoranjan A, Shrestha SM. Strabismus in Generations and Among Siblings. MJSBH. 2021;20(1):65-9.

Conflict of Interest: None declared

\section{REFERENCES}

1. Hirschberg J: History of Ophthalmology, vol 1. Translated by Blodi FC. Bonn, Wayenbergh, $1982 ; 110$.

2. Loren B. Genetics of isolated and syndromic strabismus: Facts and perspectives. Strabismus 2002;10:147-56. https://doi.org/10.1076/stra.10.2.147.8133

3. Paul TO, Hardage LK. The heritability of strabismus. Ophthalmic Genet.1994;15(1):1-8. DOI: $10.3109 / 13816819409056905$

4. Matsuo T, Hayashi M, Fujiwara H, Yamane T, Ohtsuki H. Concordance of strabismic phenotypes in monozygotic versus multizygotic twins and other multiple births. Jpn Journal Ophthalmol. 2002;46(1):59-64. DOI:10.1016/ s0021-5155(01)00465-8

5. Crone RA, VELZEBOER M. Strabismus in Statistics on Strabismus the Amsterdam Youth: Researches into the Origin of Strabismus. AMA arch ophthalmol. 1956;55(4):455-70. DOI:10.1001/archopht.1956.00930030459002

6. Maumenee IH, Alston A, Mets MB, Flynn JT, Mitchell TN, Beaty TH. Inheritance of congenital esotropia. Trans Am Ophthalmol Soc. 1986;84:85. PMCID: PMC1298727

7. Schlossman A, Priestley BS. Role of heredity in etiology and treatment of strabismus. AMA arch ophthalmol. 1952;47(1):1-20. DOI:10.1001/archopht.1952.01700030004001 
8. Parikh V, Shugart YY, Doheny KF, Zhang J, Li L, Williams J, Hayden D, Craig B, Capo H, Chamblee D, Chen C. A strabismus susceptibility locus on chromosome 7p. PNAS. 2003;100(21):12283-8. DOI: https://doi.org/10.1073/ pnas. 2035118100

9. Hegmann JP, Mash AJ, Spivey BE. Genetic analysis of human visual parameters in populations with varying incidences of strabismus. American journal of human genetics. 1974;26(5):549.

10. Engle EC. Genetic basis of congenital strabismus. Arch Ophthalmol. 2007;125(2):189-95. DOI:10.1001/archopht. 125.2.189

11. Nordloew W. Squint: the frequency of onset at different ages and the incidence of associated defects in a Swedish Population. Acta Ophthalmol (Copenh).1964;42:1015-37. DOI: https://doi.org/10.1111/j.1755-3768.1964.tb03667.x

12. Ing M Pang S. The racial distribution of strabismus. In: Strabismus:Proceedings of the Third Meeting of the International Strabismological Association. New York, NY Grune \& Stratton1978.

13. $\mathrm{Hu} \mathrm{DN}$. Prevalence and mode of inheritance of major genetic eye diseases in China. J Med Genet. 1987;24:584-8.

14. Chew E, Remaley NA, Tamboli A, Zhao J, Podgor MJ, Klebanoff M. Risk factors for esotropia and exotropia. Arch Ophthalmol. 1994;112:1349-55. DOI:10.1001/archopht.1994.01090220099030

15. Chew CK, Foster P, Hurst JA, Salmon JF. Duane's retraction syndrome associated with chromosome 4q ${ }^{27-31}$ segment deletion. Am J Ophthalmol. 1995;119:807-9. DOI: https://doi.org/10.1016/S0002-9394(14)72795-3

16. Scott MH, Noble AG, Raymond WR, Parks MM, Summers CG. Prevalence of primary monofixation syndrome in parents of children with congenital esotropia. J Pediatr Ophthalmol Strabismus. 1994;31(5),298-302. DOI: https:// doi.org/10.3928/0191-3913-19940901-06

17. Podgor MJ, Remaley NA, Chew E. Associations between siblings for esotropia and exotropia. Arch Ophthalmol. 1996;114:739-44. DOI:10.1001/archopht.1996.01100130731018

18. Ziakas NG, Woodruff G, Smith LK, Thompson JR. A study of heredity as a risk factor in strabismus. Eye. 2002;16(5):509-12. DOI: 10.1038/sj.eye.6700138.

19. Aurell E, Norsell K. A longitudinal study of children with a family history of strabismus: factors determining the incidence of strabismus. Br J Ophthalmol. 1990;74(10):589-94. DOI: 10.1136/bjo.74.10.589

20. Dufier JL, Briard ML, Bonaiti C, Frezal J, Saraux H. Inheritance in the etiology of convergent squint. Ophthalmologica. 1979;179(4):225-34. DOI: https://doi.org/10.1159/000308899 